\title{
The Place and Prognostic Value of TERT Promoter Mutation in Molecular Classification in Grade II-III Glial Tumors and Primary Glioblastomas
}

\author{
Neslihan Kaya TERZI' (D), Ismail YILMAZ² ${ }^{\mathbb{D}}$, Aysim Buge OZ ${ }^{3}$ \\ Department of Pathology, 'University of Health Sciences Gaziosmanpasa Research and Training Hospital, ISTANBUL, TURKEY, ${ }^{2}$ University of Health Sciences, \\ Sultan 2. Abdulhamid Han Research and Training Hospital, ISTANBUL, TURKEY, ${ }^{3}$ University of Cerrahpasa, Cerrahpasa Medical Faculty, ISTANBUL, TURKEY
}

The study was presented at 31 $1^{\text {st }}$ European Congress of Pathology, 7-11 September 2019 at the Nice Acropolis Convention Centre.

\section{ABSTRACT}

Objective: Diffuse gliomas, the most common primary malignant brain tumors, have been classified by the World Health Organization as class II-IV gliomas. After 2016, two mutations in the promoter region of the telomerase reverse transcriptase (TERT) gene were identified in addition to the IDH, $1 \mathrm{p} / 19 \mathrm{q}$, and ATRX status.

Material and Method: We identified 84 patients with grade II-IV glioma with IDH, ATRX, 1p / 19q and TERT status. All tumor samples were subjected to molecular genetic screening (Sanger sequencing for IDH and TERT mutations, fluorescence in situ hybridization for 1p/19q status) after histological diagnosis (immunohistochemistry for IDH1 R132H, ATRX, and p53) for a more precise molecular diagnosis. The confidence intervals were calculated at the $95 \%$ confidence level, and differences at $\mathrm{p}<0.05$ were considered statistically significant.

Results: Primary glioblastomas had the highest frequency of TERT promoter mutations ( 25 of $28,89.2 \%$, $\mathrm{p}=0.006)$ followed by oligodendrogliomas ( 29 of $35,82.8 \%, p<0.001)$ while astrocytomas showed the lowest frequency ( 3 of $15,20 \%, p=0.107$ ), and the positivity significantly differed among these three groups $(\mathrm{p}<0.001)$. TERT promoter mutations were more frequent in patients older than 55 years of age at diagnosis $(\mathrm{p}=0.023)$. The group with TERT promoter mutations, and without $I D H$ mutations showed the worst overall survival. However, the presence of both TERT promoter and $I D H$ mutations, which resembled oligodendroglial progression, showed best overall survival ( $\mathrm{p}=0.042)$.

Conclusion: The discovery of TERT promoter mutations in numerous gliomas has opened the door for a better molecular classification of gliomas, and TERT status is associated with survival. Further studies will help in elucidating the value of TERT promoter mutations as biomarkers in clinical practice, and eventual therapeutic targets.

Keywords: Diffuse glioma, Primary glioblastoma, TERT p, Promoter mutation, Survival

\section{INTRODUCTION}

Diffuse gliomas, the most common primary malignant brain tumors, have been classified by the World Health Organization (WHO) as class II-IV gliomas (1). After 2016, increasing and broad characterization of the genomic structure of gliomas has led to the identification of genetic and epigenetic markers useful for the molecular classification of these tumors (2). In addition to the IDH, $1 \mathrm{p} / 19 \mathrm{q}$, and ATRX status, two mutations in the promoter region of the telomerase reverse transcriptase (TERT) gene were frequently identified (3). The mutation in the promoter region of this gene was first discovered in melanoma (4). In 2013, TERT promoter mutations were included in the molecular classification of gliomas (3). TERT is an important unit of the telomerase complex. It is known that upregulation of TERT increases telomerase activity, the basic survival ability of cancer cells, which allows for

(Turk Patoloji Derg 2022, 38:90-98)

Received : 28.05.2021 Accepted : 24.07.2021 unlimited expansion of telomeres, and immortalization of cells (5). The mutation takes place in one of the two hot spots of the TERT gene, C228T and C250T, as C-T transition (6).

TERT mutations are usually investigated by sequencing or real-time PCR (7), and TERT promoter mutations occur in $70-80 \%$ of glioblastomas (GBM), $95 \%$ of oligodendrogliomas (OD), and $10-25 \%$ of astrocytomas (5). TERT promoter mutations are significantly inversely proportional to IDH1 / 2 mutations (8). Changes in TERT and IDH are not only associated with specific histological glioma subgroups, but also are associated with a variable prognosis (9).

The literature on telomere-related mechanisms with glioma is rapidly increasing. Their prognostic and predictive roles are very interesting and may guide the clinical management

Correspondence: Neslihan KAYA TERZI

University of Health Sciences, Gaziosmanpasa Research and Training

Hospital, Department of Pathology, ISTANBUL, TURKEY

E-mail: neslihankaya88@hotmail.com Phone: +90 5556045868 
of glioma patients. Yet, there are no studies investigating the distribution and significance of TERT promoter mutations in the WHO 2016 classification (10).

In the study conducted at Mayo Clinic, cases with $1 / 19 \mathrm{q}$ co-deletion, IDH mutation and TERT promoter mutation (triple-positive) were associated with an oligodendroglial phenotype and showed better overall survival (OS). Lowgrade tumors (II and III) showing TERT and IDH mutations without $1 \mathrm{p} 19 \mathrm{q}$ co-deletion tended to have a prognosis similar to triple-positive cases (11). However, patients without TERT and IDH mutations and those with $1 \mathrm{p} / 19 \mathrm{q}$ co-deletion had very aggressive tumors and poor survival. Patients with wild-type (WT) TERT, IDH, and persevered 1p19q (triple negative) were associated with GBM, and had worse prognosis than triple-positive gliomas, but had a better prognosis than in patients with TERT mutations only (12).

\section{MATERIALS and METHODS}

This study was approved by the medical ethics committee of the University of Health Sciences, Samatya Training Hospital (Approval No.: 06.07.2018 / 1337), and it was conducted according to the Declaration of Helsinki Principles.

\section{Study Population}

We identified 84 patients ( 32 females and 52 males) with grade II-IV glioma with known IDH, ATRX, 1p / 19q and TERT status. Fifty-seven patients had WHO grade II-III tumors (24 oligodendrogliomas (OD), 14 anaplastic ODs, 13 astrocytomas, 5 anaplastic astrocytomas, and 1 anaplastic oligoastrocytoma with a low grade glioma component), and the remaining 27 samples represented high grade glioma (WHO grade IV/GBM) (Table I).

All tumor samples were subjected to molecular genetic screening after histological diagnosis for a more precise / molecular diagnosis $(13,14)$. Tumors in the astrocytoma group were characterized by detectable immunoreactivity for IDH1 (R132H), p53 and loss of immunoreactivity for ATRX (15). All tumors in the OD group had IDH1 mutation $(\mathrm{R} 132 \mathrm{H})$ and $1 \mathrm{p} / 19 \mathrm{q}$ co-deletion. GBMs were IDH wild type (IDH-WT) (1).

\section{Immunohistochemistry (IHC), Assessment of TERT promoter and IDH Mutation, Fluorescence in situ Hybridization (FISH)}

Immunohistochemistry (IHC) was performed on at least one representative block using primary antibody against the following antigens- IDH1 R132H (Dianova, dilution
Table I: Clinicopathological variables of the 84 diffuse glioma patients.

\begin{tabular}{|c|c|}
\hline Demographics & n (\%) \\
\hline \multicolumn{2}{|l|}{ Gender } \\
\hline Male & $52(61.9)$ \\
\hline Female & $32(38.1)$ \\
\hline Age $(y)$, mean \pm SD & $44.68 \pm 14.127$ \\
\hline$\leq 55$ & $65(77.3)$ \\
\hline$>55$ & $19(22.6)$ \\
\hline \multicolumn{2}{|l|}{ Tumor location } \\
\hline Frontal & $48(65.7)$ \\
\hline Midline & $16(21.9)$ \\
\hline Others & $9(12.3)$ \\
\hline \multicolumn{2}{|l|}{ WHO 2016 diagnosis } \\
\hline Diffuse astrocytoma, IDH-mutant & $10(11.9)$ \\
\hline Diffuse astrocytoma, IDH-wildtype & $3(3.5)$ \\
\hline Anaplastic astrocytoma, IDH-mutant & $4(4.7)$ \\
\hline Anaplastic astrocytoma, IDH-wildtype & $0(0)$ \\
\hline $\begin{array}{l}\text { Oligodendroglioma, IDH-mutant \& } \\
\text { 1p/19q-codeleted }\end{array}$ & $23(27.3)$ \\
\hline $\begin{array}{l}\text { Anaplastic oligodendroglioma, IDH- } \\
\text { mutant \& 1p/19qcodeleted }\end{array}$ & $14(16.6)$ \\
\hline Oligodendroglioma, NOS & $1(1.1)$ \\
\hline $\begin{array}{l}\text { Anaplastic oligoastrocytoma, IDH- } \\
\text { mutant \& 1p/19qcodeleted }\end{array}$ & $1(1.1)$ \\
\hline Glioblastoma, IDH-mutant & $0(0)$ \\
\hline Glioblastoma, IDH-wildtype & $28(33.3)$ \\
\hline \multicolumn{2}{|l|}{ Surgery } \\
\hline Biopsy only & $10(11.9)$ \\
\hline Total resection & $74(88)$ \\
\hline \multicolumn{2}{|l|}{ Adjuvant treatment } \\
\hline None & $4(4.7)$ \\
\hline Chemoradiation & $80(95.2)$ \\
\hline \multicolumn{2}{|l|}{ Survival outcome } \\
\hline Alive & $61(72.6)$ \\
\hline Deceased & $19(22.6)$ \\
\hline
\end{tabular}

SD: Standard deviation

1:40), ATRX (Sigma, dilution 1:300), and p53 (Dako, dilution 1:50). Cases showing cytoplasmic positivity for IDH1 in tumor cells were considered positive. Loss of nuclear staining for ATRX in tumor cells $(>90 \%)$ was considered positive for ATRX mutation. Nuclear positivity for p53 in $>10 \%$ tumor cells was considered positive (16). 
Mutations in the promoter region of TERT gene (chr5, $1,295,228 \mathrm{C}>\mathrm{T}$ and $1,295,250 \mathrm{C}>\mathrm{T}$ ) and exon 4 of IDH1 and IDH2 genes (well-known hotspot regions for oncogenic mutations) were analyzed by PCR-based direct sequencing using representative formalin-fixed paraffin-embedded tumor samples. Tumor targets were manually microdissected from $5-\mu \mathrm{m}$ thick unstained histological sections. After deparaffinization and rehydration, DNA was isolated from each target using QIAamp DNA FFPE Tissue Kit (50) (catalog \#: 56404) (QIAGEN, Hilden, Germany) in accordance with the manufacturer's instructions. DNA concentrations of samples were assessed spectrophotometrically using a Nanodrop 1000 spectrophotometer (Thermo Scientific, USA). PCR was performed in a Thermal Cycler (ABI, Applied Biosystems, USA) using HotStarTaq DNA Polymerase kit (catalog \#: 203205) (QIAGEN, Hilden, Germany), and appropriate primers (TERT -Forward: 5'CAGCGCTGCCTGAAACTC'3, TERT -Reverse: 5'GTCCTGCCCCTTCACCTT'3, IDH1 exon 4-Forward: 5' CCAAGTCACCAAGGATGCTG'3, IDH1 exon 4-Reverse: 5' TCACATTACTGCCAACATGACTT'3, IDH2 exon 4-Forward: 5' CCGTCTGGCTGTGTTGTTG'3, and IDH2 exon 4-Reverse: 5’ AGTCTGTCGCCTTGTACTGC’3).

PCR reactions were run as total volume of $50 \mu \mathrm{l}$ reaction mixtures consisting of nuclease free water, $5 \mu \mathrm{l} 10 \mathrm{x}$ PCR Buffer, $10 \mu \mathrm{l}$ Q solution (for TERT), $1.5 \mu \mathrm{l} 10 \mathrm{mM} \mathrm{dNTP}$ mix (ABI, Applied Biosystems, USA), $2 \mu l 25 \mathrm{mM} \mathrm{MgCl}$ (for IDH1 and IDH2), $7 \mu \mathrm{l}$ (for TERT) and $6 \mu \mathrm{l}$ (for IDH1 and $I D H 2)$ of each primer ( $4 \mathrm{pmol} / \mu \mathrm{l}), 0.25 \mu \mathrm{l}$ of Hot Start Taq DNA polymerase, and $50 \mathrm{ng}$ of each tumor DNA. After an initial denaturation at $95^{\circ} \mathrm{C}$ for 15 minutes, 42 cycles were performed of 30 seconds denaturation at $95^{\circ} \mathrm{C}$, 30 seconds annealing at $55^{\circ} \mathrm{C}$ (for TERT), and at $58^{\circ} \mathrm{C}$ (for $I D H 1$ and $I D H 2$ ), and 45 seconds extension at $72^{\circ} \mathrm{C}$, followed by a final extension of 10 minutes at $72^{\circ} \mathrm{C}$. The intensity of the PCR products were checked by running 5 $\mu \mathrm{l}$ of each PCR reaction with $2 \mu \mathrm{l}$ of loading dye on a $2 \%$ agarose gel. Reagent contamination control was achieved by examining the lane for "No DNA" blank tube. Then, all succeeded PCR products were purified using the QIAquick PCR Purification Kit (catalog \#: 28106) (QIAGEN, Hilden, Germany) according to the manufacturer's instructions. The purified amplicons were submitted to direct sequencing in both directions (forward and reverse) using reagents from the Big Dye Terminator v3.1 Cycle Sequencing kit (ABI, Applied Biosystems, USA) in accordance with the manufacturer's protocol. After ethanol precipitation, subsequent products were run on the ABI-3730 (48 capillary) automatic sequencer (Applied Biosystems, USA).
Bidirectional sequence traces were analyzed with SeqScape ${ }^{\oplus}$ Software v3.0 (Applied Biosystems, USA), and manually reviewed.

FISH analysis was performed on 5-micron-thick formalin fixed paraffin-embedded tissue samples. Deparaffinization, pre-hybridization and hybridization steps were conducted according to the datasheet. One hundred tumors cells were analyzed on the fluorescent microscope (Olympus BX61; Olympus Optical, Japan). The cells were captured on a computer system with a digital camera (XLMM, DageMTI, IN, USA), and compatible software (Duet ${ }^{\bullet}$, Bioview Ltd., Israel). Dual-color paired probes for $1 \mathrm{p}$ and 1q (1p36 Spectrum Orange and 1q25 Spectrum Green, Vysis LSI probes, Abbott Molecular, Des Plaines, IL) were hybridized simultaneously on one slide, and similarly those for $19 \mathrm{q}$, and 19p (19q13 Spectrum Orange and 19p13 Spectrum Green, Vysis LSI probes, Abbott Molecular, Des Plaines, IL) were used on a separate slide. A proportion is used due to the fact that a significant number of nuclei would have reduced comparison/control (green) signals because of tissue sectioning removing portions of the nuclei. Based on laboratory experience, a proportion $<0.80$ was considered as a deletion. The ratio of SpectrumOrange to SpectrumGreen signals (total orange/total green) was calculated.

\section{Statistical Analysis}

Statistical analyses were performed using IBM SPSS Statistics for Windows, Version 21.0. (IBM Corp., Armonk, NY). Descriptive statistics were used to describe the data. Normal distribution was tested by the KolmogorovSmirnov and Shapiro-Wilk tests. Non-parametric data were compared using the Chi-square test. The Kaplan-Meier method was used for survival analysis, and the log-rank test (Mantel-Cox) was performed to compare the survival curves between the groups. The confidence intervals were calculated at the $95 \%$ confidence level and differences at $\mathrm{p}$ $<0.05$ were considered statistically significant.

\section{RESULTS}

\section{Clinicopathologic Demographics}

A total of 84 patients consisting of 52 men (61.9\%) and 32 women (38.1\%) were recruited. Their mean age was 44.68 \pm 14.12 years (range $12-82$ years). The mean duration of follow-up was 24-60 months. There were 65 patients (77.3\%) aged less than 55 years, and 19 patients (22.6\%) older than 55 years. The WHO 2016 revised diagnosis of the study group was as follows: 10 diffuse astrocytomas IDH-mutant (11.9\%); 3 diffuse astrocytomas- IDH-WT (3.5\%); 4 anaplastic astrocytomas- IDH-mutant (4.7\%); 23 ODs-IDH-mutant, and 1p/19q codeleted (27.3\%); 14 
anaplastic ODs, IDH-mutant \& 1p/19q-codeleted (16.6\%); 1 OD NOS (1.1\%); 1 anaplastic oligoastrocytoma (1.1\%), and 28 GBM-IDH-WT (33.3\%). Biopsy was carried out only in 10 patients (11.9\%), and debulking surgery was performed in 74 patients (88\%). 80 patients (95.2\%) were treated with some form of adjuvant radiotherapy and/ or chemotherapy, while $4(4.7 \%)$ patients did not receive any adjuvant radio-chemotherapy. 61 patients were alive (72.6\%) while 19 patients (22.6\%) died (Table I).

\section{TERT Promoter Mutations and Alterations in Other Genes}

Overall, TERT promoter mutations were present in 57 of $84(67.9 \%)$ gliomas [20 (60.6\%) in grade II, $12(66.6 \%)$ in grade III, and 25 (92.5\%) in grade IV]. The C228T mutation was detected in 42 tumors (53.8\%), whereas the C250T mutation was found in 15 cases (19.2\%), supporting the predominance of the C228T mutation in glioma. Primary glioblastomas had the highest frequency of TERT promoter mutations $(25 / 28 ; 89.2 \%, \mathrm{p}=0.006)$ followed by oligodendrogliomas $(29 / 35 ; 82.8 \%, \mathrm{p}<0.001)$, while astrocytomas showed the lowest frequency, with 3 out of $15(20 \%, \mathrm{p}=0.107)$ samples showing mutations (Table II). TERT promoter mutations were found to be associated with high grade (grade III/IV) tumors when compared to lower grade (grade II) lesions $(\mathrm{p}<0.033)$, and were more frequent in patients older than 55 years of age $(\mathrm{p}=0.023)$. A statistically significant association was observed between the TERT mutation and the diagnosis $(\mathrm{p}<0.001)$. We performed post hoc power analysis by $\mathrm{G}^{*}$ Power 3.1.9.2. The Type II error $(\beta)$ probability was less than 0.01 (power $>0.99$ ) for the combined diagnostic algorithm (Figure 1).

IDH gene mutations were present in 44 tumors (42 of these being $I D H 1 \mathrm{R} 132 \mathrm{H}$ mutations). Twenty-nine of these (corresponding to oligodendrogliomas) harbored a concomitant $1 \mathrm{p} / 19 \mathrm{q}$ co-deletion, and all of them except three were also TERT promoter mutant.
The TERT p mutation and IDH mutation were more highly associated compared to TERT $\mathrm{p}$ with IDH-WTs $(\mathrm{P}<0.001$ and $\mathrm{p}=0.655$, respectively). However, in oligodendroglial tumors, TERT promoter and IDH mutations occurred together $(\mathrm{p}<0.001) .24$ of 26 IDH/TERT double mutant tumors had the $1 \mathrm{p} / 19 \mathrm{q}$ co-deletion. In primary glioblastomas, there were no $I D H$ mutations, as expected. In astrocytomas, TERT promoter and $I D H$ mutations were both found in only 2 of 15 cases (Figure 2).

Moreover, TERTP and TP53 mutations in low-grade and anaplastic gliomas were mutually exclusive, where none and $5.5 \%$ of TERT mutated tumors harbored TP53 mutations, respectively. A statistically significant association was observed between the TERT mutation and p53 mutation $(\mathrm{p}<0.001)$.

TERT promoter mutations were mutually exclusive with ATRX deficiency. However, no statistically significant association was observed between the TERT mutation and ATRX mutation $(\mathrm{p}=0.533)$.

\section{Effect of TERT Promoter Mutations on Survival}

Results of the Kaplan-Meier survival analysis are shown in Figure $3 \mathrm{~A}, \mathrm{~B}$.

The overall cumulative survival in cases with TERT mutation was 64.94 months (95\% $\mathrm{CI}=55.58-74.31)$ and overall cumulative survival in cases without TERT mutation was 46.80 months (95\% CI=37.71-55.89) ( $\mathrm{p}=0.870)$ (Figure $3 \mathrm{~B})$. Patients carrying the C250T mutation had slightly longer survival compared to patients with the C228T mutation (78.5\% and $76.9 \%)$.

Moreover, the TERT mutation frequency, both C228T and C250T, increased with age: $<40$ years: $65.5 \%(19 / 29)$; 40-55 years: $66.6 \%$ (20/30), and $>55$ years: $94.7 \%(18 / 19)$. Compared to patients with WT- TERT, younger patients with TERT mutation survived longer, but patients with TERT mutation who were aged $>55$ years had shorter survival.

Table II: The frequency of TERTp mutations.

\begin{tabular}{lccc}
\hline Diagnosis & C228T mutation & C250T mutation & Both TERT mutations \\
\hline OD, $I D H$ mutant & $\mathbf{n ~ ( \% )}$ & $\mathbf{n}(\%)$ & $\mathbf{n}(\%)$ \\
\hline OD, $I D H$ wildtype & $18 / 23(78.2)$ & $5 / 23(21.7)$ & $23 / 26(88.4)$ \\
\hline A-AA, $I D H$ mutant & $1 / 2(50)$ & $1 / 2(50)$ & $2 / 4(50)$ \\
\hline A, $I D H$ wildtype & $1 / 2(50)$ & $1 / 2(50)$ & $2 / 12(16.6)$ \\
\hline GBM, $I D H$ wildtype & $1 / 1(100)$ & $0(0)$ & $1 / 2(50)$ \\
\hline
\end{tabular}

OD: Oligodendroglioma, A: Astrocytoma, AA: Anaplastic astrocytoma, GBM: Glioblastoma. 

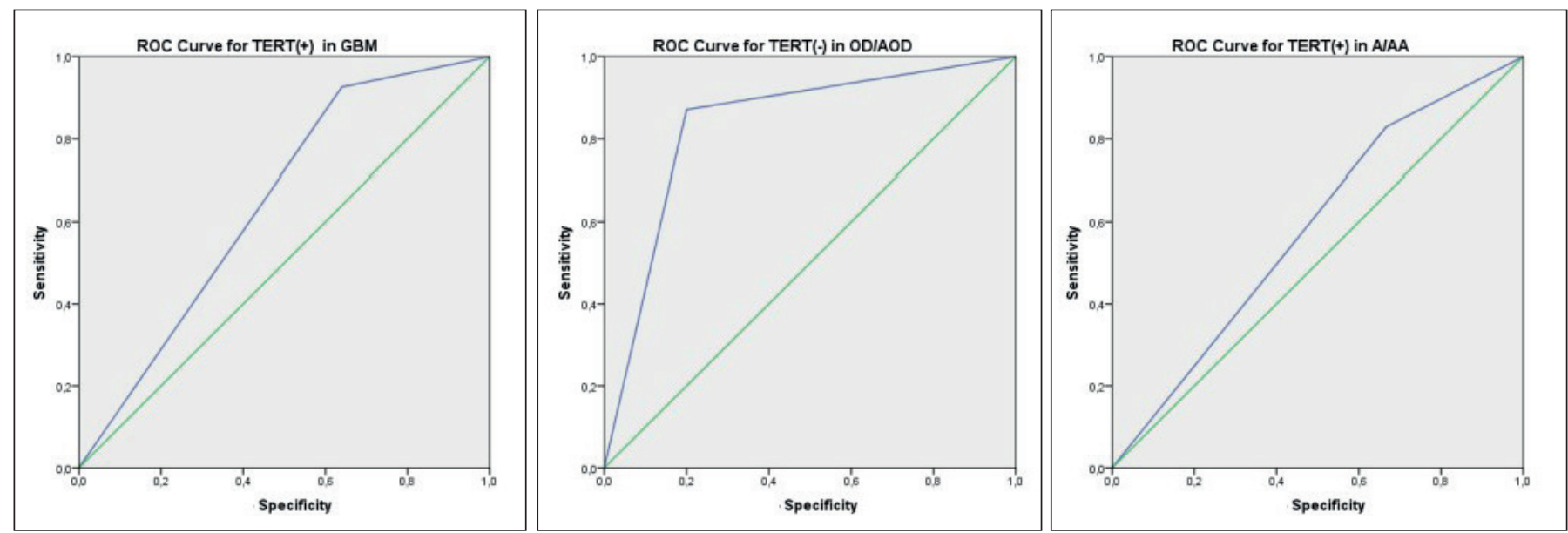

Figure 1: Specificity and sensitivity of TERT mutation in glioblastoma, oligodendroglioma / anaplastic oligodendroglioma, and astrocytoma / anaplastic astrocytoma.

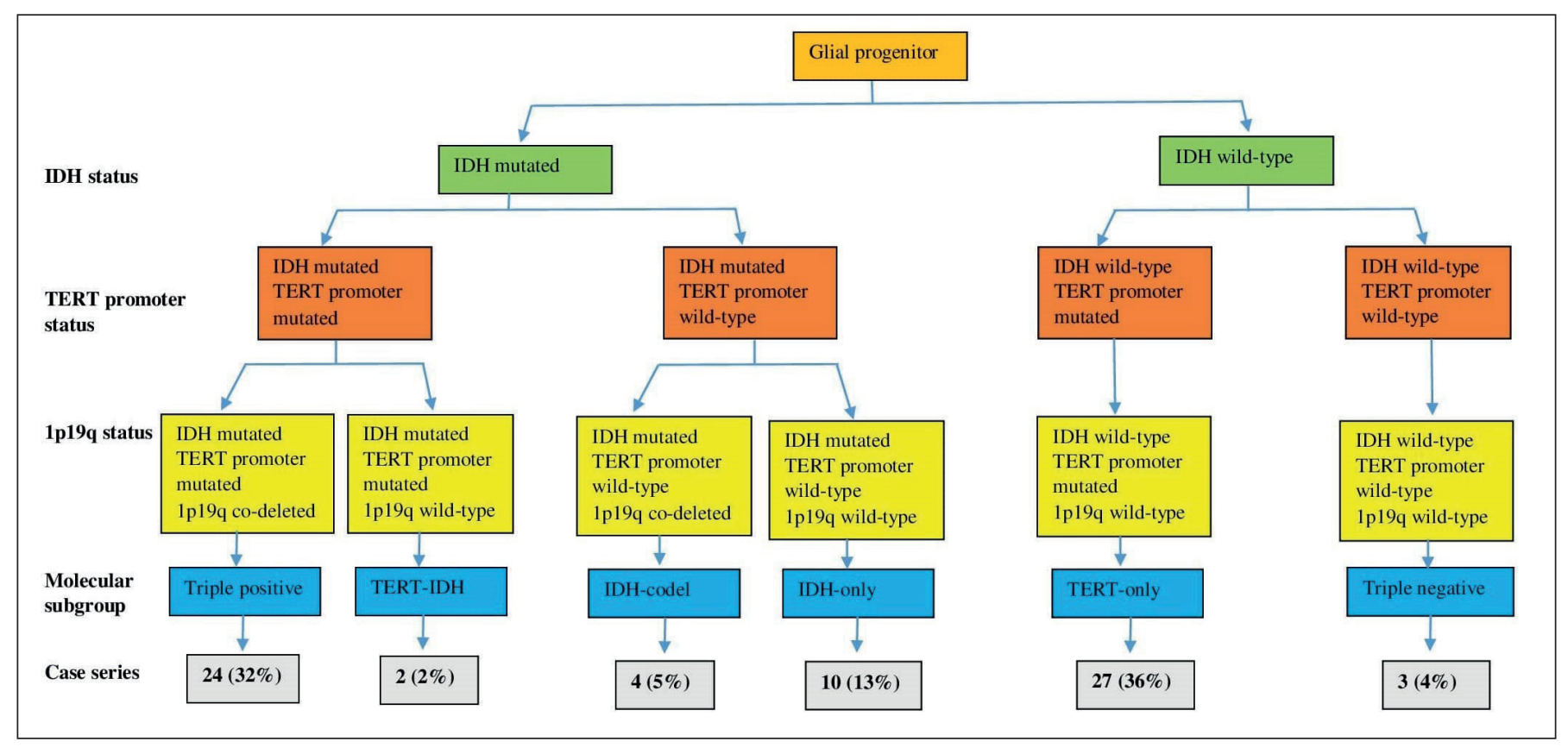

Figure 2: Molecular classification of diffuse glioma and frequency of each subgroup in our study.

Stratification of the patients based on the mutational status of TERT promoter and IDH resulted in three groups with different overall survival. The group with TERT promoter mutations and no IDH mutations had the worst overall survival (median survival 12.29 months), the 2nd worst overall survival rate was the group without TERT and IDH mutations (median survival 24 months). Best overall survival was associated with the presence of both TERT promoter and IDH mutations (median survival 38.07 months), which resembles oligodendroglial progression $(\mathrm{p}=0.042)$.
Survival analysis in patients with primary glioblastomas did not reveal any effect of the TERT promoter mutations. Both patients with and without TERT promoter mutations had a median survival of 12 months (Figure 3A).

In diffuse and anaplastic gliomas that showed TERT promoter mutations were associated with poor survival while $1 \mathrm{p} / 19 \mathrm{q}$ co-deletions had a favorable effect. Survival in gliomas with a TERT mutation and $1 \mathrm{p} 19 \mathrm{q}$ co-deletion (median survival 58.2 months) was higher than in those without TERT mutation and 1p19q codeletion (median survival 42 months). 

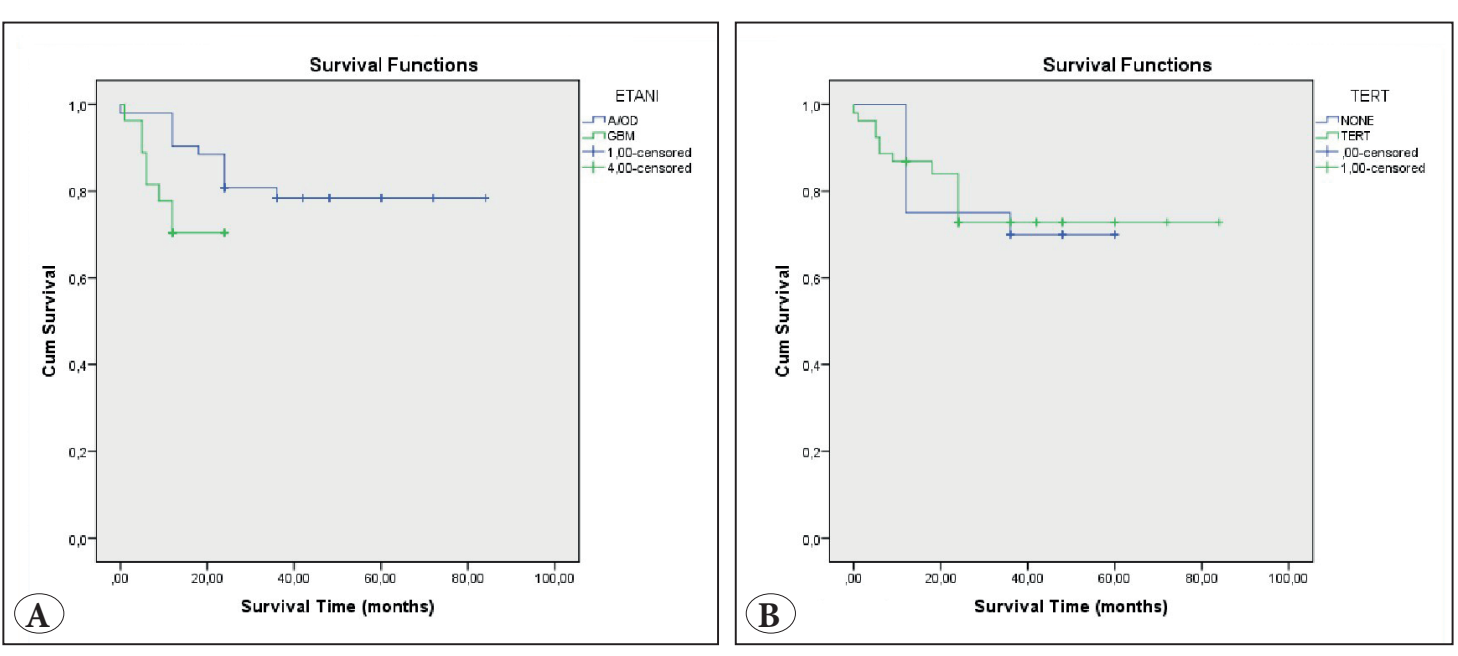

Figure 3: Survival times of anaplastic oligodendroglioma and glioblastoma cases (A). Survival times of cases with TERT mutation (B).

\section{DISCUSSION}

Gliomas are the most common and aggressive primary brain tumors in adults (2). For diffuse gliomas, $I D H$ mutations and $1 \mathrm{p} / 19 \mathrm{q}$ co-deletion constitute the main components of the integrated WHO 2016 diagnosis. Molecular classifications proposed in the literature include the combination of the IDH mutations, the $1 \mathrm{p} / 19 \mathrm{q}$ codeletion, and the telomere maintenance mechanism as defined by alterations in TERT (15). To determine whether the TERT status provides additional prognostic information, we analyzed the relationship between overall survival in glioma patients classified according to the WHO 2016 criteria in our cohort.

Recent studies have shown that this classification has certain limitations for precise prediction of clinical outcomes and strategies for gene target therapy (16). Therefore, a more objective glioma classification is needed to guide diagnosis and treatment strategies.

Telomeres are structures at the end of eukaryotic chromosomes and are responsible for the deterioration of chromosomes, end-to-end fusion, and protection from rearrangement (17). Telomerase maintains the appropriate telomere length by adding repeated telomeric sequences to the 3' ends of the telomeres. Abnormal telomerase activity plays a role in the initiation and development of cancer and other diseases related to aging (18). TERT is overexpressed in many human cancers (19). TERT promoter mutations were first found in melanoma and were thought to represent the tumorigenic mechanism (16).

The discovery of TERT $\mathrm{p}$ mutations in numerous gliomas has opened the door for a better molecular classification of gliomas in 2013 (20,21). TERT promoter mutations occur in $70-80 \%$ of glioblastomas, $95 \%$ of oligodendrogliomas, and $10-25 \%$ of astrocytomas $(5,7,11)$.
The prevalence of TERT promoter mutations associated with various histological categories was similar to other studies $(22,23)$. As expected, IDH-mutant tumors were prevalent predominantly in younger adults, while all IDH-WT/ TERT -mutant tumors apart from a single pediatric tumor occurred in adults. Our findings are consistent with the concept that IDH-WT/ TERTmutant diffuse gliomas represent a clinicopathological part of primary glioblastomas and their precursors (24, 25). In any case, inclusion of TERT promoter mutation analysis into a diagnostic molecular panel shifts the vast majority of otherwise marker-negative diffuse gliomas into a biologically plausible category. Furthermore, TERT promoter mutation status is of prognostic significance not only in diffuse gliomas with non-glioblastoma histology $(11,25)$, but also in glioblastoma $(10,26)$. The present study demonstrates that adding the TERT promoter mutation status to standard markers, as suggested in the literature, results in a precise molecularly directed classification with IDH-WT/ TERT -mutant tumors representing the primary glioblastoma group (27).

Age was another parameter for survival. Patients aged $>55$ years who had TERT mutation had worse survival compared to patients without the mutation.

In the whole cohort, patients with C250T mutations tended to have longer survival compared to patients with C228T mutations. We found that occurrence of the C228T and C250T mutations were mutually exclusive in our cohort, and that C228T (84.2\%) was more common than C250T $(15.8 \%)$.

With rare exceptions, TERT promoter mutations (8), which lead to an increase in telomerase expression, and inactivating mutations in the thalassemia/mental retardation syndrome X-linked (ATRX) gene, are mutually 
exclusive, and are associated with different molecular tumor subclasses (28). Our study was the exception for mutual relationship of ATRX and TERT mutations, as we could not find any significant relationship $(\mathrm{p}=0.533)$. On the other hand, our study demonstrated that TERT promoter mutations have a significant inverse association with P53 mutation $(\mathrm{p}<0.001)$, similar to previous studies (17).

TERT promoter mutations have been reported to be associated with aggressive behavior and poor outcome in various types of cancers (3). In this study, prognosis in glioblastoma cases with TERT mutation was worse than in oligodendrogliomas with TERT mutation. Cases with TERT mutation had a worse prognosis than cases without TERT mutation, but none of the relevant results in our study had statistical significance.

The combination of TERTp and IDH mutational status was a significant prognostic factor in grade II and III gliomas; this finding of a specific association between IDH/ TERTp group and low-grade glioma is consistent with results from a previous study $(20,29)$. Eckel-Passow et al. (12) showed that patients with IDH-WT/TERTp-WT have poorer overall survival when compared with patients with $I D H$ mutated/TERTp or IDH mutation alone, but showed better overall survival when compared with patients with $I D H$ WT/TERTp-mutation (11). A recently published metaanalysis also suggested that combined TERTp-mutated/ $\mathrm{I} D H$-WT testing could act as a significant biomarker for poor prognosis in grade II and III gliomas (20).

Given that $67.9 \%$ of tumours being TERTp-mut, TERT is the most frequently mutated gene in gliomas thus far identified $(5,8,30-32)$. Our data confirm the high frequency of TERTp-mutation in gliomas, and show that these mutations clusterise into specific entities, with distinct clinical significances.

In previous studies, the $1 \mathrm{p} / 19 \mathrm{q}$ co-deletion was strongly associated with mutations in TERTp $(33,34)$. In the present study, we found that $96.9 \%$ of patients with oligodendrogliomas had a TERTp mutation, whereas two patients with oligodendroglioma were TERTp-WT. On the contrary, there was a high frequency of TERTp mutation in cases with GBM that did not harbor the $1 \mathrm{p} / 19 \mathrm{q}$ co-deletion, and therefore we conclude that the TERTp mutation is not exclusively associated with the $1 \mathrm{p} / 19 \mathrm{q}$ co-deletion.

Regarding the TERTp mutation from a prognostic perspective in diffuse gliomas, previous studies have shown conflicting results. Labussiere et al. have found that TERTp mutations may be associated with poorer outcome in high- grade gliomas (31), however, Pekmezci et al. have reported that TERT-mutants had significantly worse survival only in IDH-WT astrocytoma, which includes grades II and III (10). Such contradictory effects of TERTp mutation on patient outcome between groups have been reported previously (11). Aibaidula et al. found comparable results to those of Pekmezci et al., and concluded that adult IDHWT lower-grade gliomas should be further classified by TERTp mutation status (35).

According to Cimpact now update 3, IDH wild type diffuse or anaplastic astrocytomas will have a worse prognosis as grade IV glioblastomas. The following molecular methods can be used to distinguish these cases: EGFR amplification, losses of chromosome 10 (whole chromosome, 10p or 10q), gains of chromosome 7 (whole chromosome, $7 p$ or $7 \mathrm{q})$, TERT promoter mutations, homozygous deletion of $\mathrm{CDKN} 2 \mathrm{~A} / \mathrm{B}$, and large-scale, microarray based DNA methylation profiling. According to the results of the current study, histologic IDH-wildtype diffuse astrocytic gliomas of WHO grade II or III that carry EGFR amplification, $+7 /-10$ or TERT promoter mutation are associated with significantly shorter survival compared to patients with other WHO grade II or III gliomas, and outcomes are similar to those in patients with IDHwildtype glioblastoma (27). Molecular studies other than TERT promoter mutation could not be performed, and this is a limitation of our study. We aim to fill this gap in future studies.

IDH mutation was detected in 16 cases with midline localization in our study and their grade was II. In these cases, which are known to have a good prognosis in followup, diffuse midline glioma was evaluated by considering it in the differential diagnosis. However, H3F3A K27M mutation could not be detected with immunohistochemical or molecular methods.

TERT promoter mutations were shown to have inverse prognostic effects in IDH-mut and IDH-WT WHO grade II/III gliomas. Our study strongly supports using TERT and IDH genotyping in WHO grade II/III gliomas as a reliable and reasonable test that can help clinicians predict patient outcome more precisely than using only conventional histology, or TERT or IDH status alone. It is important to note that gliomas with concurrent TERT promoter and $I D H$ mutations are almost always accompanied with $1 \mathrm{p} 19 \mathrm{q}$ co-deletion, which is the hallmark of oligodendroglioma according to the WHO classification 2016, and it can help to explain why gliomas with coexisting $I D H$ and TERT promoter mutations are most likely associated with favorable outcome. 
Data suggest that patients with TERT promoter mutations in tumors probably require more aggressive treatment than their WT counterparts. Further studies will help elucidating the value of TERT promoter mutations as biomarkers in clinical practice and eventual therapeutic targets. Expression data and an association with shorter telomeres already strongly indicate the role of the TERT promoter mutations not only in glioma, but in many other cancer types, and future functional studies will aid in placing the TERT promoter mutations into the right context.

\section{Acknowledgement}

The statistical part of the study was conducted by specialist pediatrician doctor Ersin Tural.

\section{Conflict of Interest}

The authors declare that they have no conflict of interest.

\section{Funding}

This study was supported by the University of Health Sciences Scientific Research Unit (Project number 2018/064).

\section{Authorship Contributions}

Concept: NKT, IY, BO, Design: NKT, IY, BO, Data collection or processing: NKT, Analysis or Interpretation: NKT, IY, BO, Literature search: NKT, IY, BO, Writing: NKT, IY, BO, Approval: NKT, IY, BO.

\section{REFERENCES}

1. Louis DN, Perry A, Reifenberger G, von Deimling A, FigarellaBranger D, Cavenee WK, Ohgaki H, Wiestler OD, Kleihues P, Ellison DW. The 2016 World Health Organization Classification of tumors of the central nervous system: A summary. Acta Neuropathol. 2016;131:803-20.

2. Louis DN, Ohgaki H, Wiestler OD, Cavenee WK, Burger PC, Jouvet A, Scheithauer BW, Kleihues P. The 2007 WHO classification of tumours of the central nervous system. Acta Neuropathol. 2007;114:97-109.

3. Vuong HG, Altibi AMA, Duong UNP, Ngo HTT, Pham TQ, Chan AK, Park CK, Fung KM, Hassell L. TERT promoter mutation and its interaction with IDH mutations in glioma: Combined TERT promoter and IDH mutations stratifies lowergrade glioma into distinct survival subgroups-A meta-analysis of aggregate data. Crit Rev Oncol Hematol. 2017;120:1-9.

4. Horn S, Figl A, Rachakonda PS, Fischer C, Sucker A, Gast A, Kadel S, Moll I, Nagore E, Hemminki K, Schadendorf D, Kumar R. TERT promoter mutations in familial and sporadic melanoma. Science. 2013; 339:959-61.

5. Arita H, Narita Y, Fukushima S, Tateishi K, Matsushita Y, Yoshida A, Miyakita Y, Ohno M, Collins VP, Kawahara N, Shibui S, Ichimura K. Upregulating mutations in the TERT promoter commonly occur in adult malignant gliomas and are strongly associated with total $1 \mathrm{p} 19 \mathrm{q}$ loss. Acta Neuropathol. 2013;126:267-76.
6. Otani R, Uzuka T, Ueki K. Classification of adult diffuse gliomas by molecular markers-a short review with historical footnote. Jpn J Clin Oncol. 2017;47:2-6.

7. Pesenti C, Paganini L, Fontana L, Veniani E, Runza L, Ferrero S, Bosari S, Menghi M, Marfia G, Caroli M, Silipigni R, Guerneri S, Tabano S, Miozzo M. Mass spectrometry-based assay for the molecular diagnosis of glioma: Concomitant detection of chromosome $1 \mathrm{p} / 19 \mathrm{q}$ codeletion, and IDH1, IDH2, and TERT mutation status. Oncotarget. 2017;8:57134-48.

8. Killela PJ, Pirozzi CJ, Healy P, Reitman ZJ, Lipp E, Rasheed BA, Yang R, Diplas BH, Wang Z, Greer PK, Zhu H, Wang CY, Carpenter AB, Friedman H, Friedman AH, Keir ST, He J, He Y, McLendon RE, Herndon JE 2nd, Yan H, Bigner DD. Mutations in IDH1, IDH2, and in the TERT promoter define clinically distinct subgroups of adult malignant gliomas. Oncotarget. 2014;5:1515-25.

9. Ceccarelli M, Barthel FP, Malta TM, Sabedot TS, Salama SR, Murray BA, Morozova O, Newton Y, Radenbaugh A, Pagnotta SM, Anjum S, Wang J, Manyam G, Zoppoli P, Ling S, Rao AA, Grifford M, Cherniack AD, Zhang H, Poisson L, Carlotti CG Jr, Tirapelli DP, Rao A, Mikkelsen T, Lau CC, Yung WK, Rabadan R, Huse J, Brat DJ, Lehman NL, Barnholtz-Sloan JS, Zheng S, Hess K, Rao G, Meyerson M, Beroukhim R, Cooper L, Akbani R, Wrensch M, Haussler D, Aldape KD, Laird PW, Gutmann DH; TCGA Research Network, Noushmehr H, Iavarone A, Verhaak RG. Molecular profiling reveals biologically discrete subsets and pathways of progression in diffuse glioma. Cell. 2016;164:550-63.

10. Pekmezci M, Rice T, Molinaro AM, Walsh KM, Decker PA, Hansen H, Sicotte H, Kollmeyer TM, McCoy LS, Sarkar G, Perry A, Giannini C, Tihan T, Berger MS, Wiemels JL, Bracci PM, Eckel-Passow JE, Lachance DH, Clarke J, Taylor JW, Luks T, Wiencke JK, Jenkins RB, Wrensch MR. Adult infiltrating gliomas with WHO 2016 integrated diagnosis: Additional prognostic roles of ATRX and TERT. Acta Neuropathol. 2017;133:1001-16.

11. Eckel-Passow JE, Lachance DH, Molinaro AM, Walsh KM, Decker PA, Sicotte H, Pekmezci M, Rice T, Kosel ML, Smirnov IV, Sarkar G, Caron AA, Kollmeyer TM, Praska CE, Chada AR, Halder C, Hansen HM, McCoy LS, Bracci PM, Marshall R, Zheng S, Reis GF, Pico AR, O’Neill BP, Buckner JC, Giannini C, Huse JT, Perry A, Tihan T, Berger MS, Chang SM, Prados MD, Wiemels J, Wiencke JK, Wrensch MR, Jenkins RB. Glioma Groups Based on 1p/19q, IDH, and TERT Promoter Mutations in Tumors. N Engl J Med. 2015;372:2499-508.

12. Labreche K, Kinnersley B, Berzero G, Di Stefano AL, Rahimian A, Detrait I, Marie Y, Grenier-Boley B, Hoang-Xuan K, Delattre JY, Idbaih A, Houlston RS, Sanson M. Diffuse gliomas classified by $1 \mathrm{p} / 19 \mathrm{q}$ co-deletion, TERT promoter and IDH mutation status are associated with specific genetic risk loci. Acta Neuropathol. 2018;135:743-55.

13. Masui K, Mischel PS, Reifenberger G. Molecular classification of gliomas. Handb Clin Neurol. 2016;134:97-120.

14. Reuss DE, Sahm F, Schrimpf D, Wiestler B, Capper D, Koelsche C, Schweizer L, Korshunov A, Jones DT, Hovestadt V, Mittelbronn M, Schittenhelm J, Herold-Mende C, Unterberg A, Platten M, Weller M, Wick W, Pfister SM, von Deimling A. ATRX and IDH1-R132H immunohistochemistry with subsequent copy number analysis and IDH sequencing as a basis for an "integrated" diagnostic approach for adult astrocytoma, oligodendroglioma and glioblastoma. Acta Neuropathol. 2015;129:133-46. 
15. Roshandel AK, Busch CM, Mullekom JV, Cuoco JA, Rogers CM, Apfel LS, Marvin EA, Sontheimer HW, Umans RA. The predictive capability of immunohistochemistry and DNA sequencing for determining TP53 functional mutation status: A comparative study of 41 glioblastoma patients. Oncotarget. 2019;10:6204-18.

16. Walsh KM, Wiencke JK, Lachance DH, Wiemels JL, Molinaro AM, Eckel-Passow JE, Jenkins RB, Wrensch MR. Telomere maintenance and the etiology of adult glioma. Neuro Oncol. 2015; 17:1445-52.

17. You H, Wu Y, Chang K, Shi X, Chen XD, Yan W, Li R. Paradoxical prognostic impact of TERT promoter mutations in gliomas depends on different histological and genetic backgrounds. CNS Neurosci Ther. 2017;23:790-7.

18. Zhou P, Wei L, Xia X, Shao N, Qian X, Yang Y. Association between telomerase reverse transcriptase rs2736100 polymorphism and risk of glioma. J Surg Res. 2014;191:156-60.

19. Gillis AJ, Schuller AP, Skordalakes E. Structure of the Tribolium castaneum telomerase catalytic subunit TERT. Nature. 2008;455:633-7.

20. Stewart SA, Weinberg RA. Telomeres: Cancer to human aging. Annu Rev Cell Dev Biol. 2006;22:531-57.

21. Kim HS, Kwon MJ, Song JH, Kim ES, Kim HY, Min KW. Clinical implications of TERT promoter mutation on IDH mutation and MGMT promoter methylation in diffuse gliomas. Pathol Res Pract. 2018;214:881-8.

22. Killela PJ, Reitman ZJ, Jiao Y, Bettegowda C, Agrawal N, Diaz LA Jr, Friedman AH, Friedman H, Gallia GL, Giovanella BC, Grollman AP, He TC, He Y, Hruban RH, Jallo GI, Mandahl N, Meeker AK, Mertens F, Netto GJ, Rasheed BA, Riggins GJ, Rosenquist TA, Schiffman M, Shih IeM, Theodorescu $\mathrm{D}$, Torbenson MS, Velculescu VE, Wang TL, Wentzensen N, Wood LD, Zhang M, McLendon RE, Bigner DD, Kinzler KW, Vogelstein B, Papadopoulos N, Yan H. TERT promoter mutations occur frequently in gliomas and a subset of tumors derived from cells with low rates of self-renewal. Proc Natl Acad Sci U S A. 2013;110:6021-6.

23. Yang P, Cai J, Yan W, Zhang W, Wang Y, Chen B, Li G, Li S, Wu C, Yao K, Li W, Peng X, You Y, Chen L, Jiang C, Qiu X, Jiang T; CGGA project. Classification based on mutations of TERT promoter and IDH characterizes subtypes in grade II/III gliomas. Neuro Oncol. 2016;18:1099-108.

24. Brandner S, von Deimling A. Diagnostic, prognostic and predictive relevance of molecular markers in gliomas. Neuropathol Appl Neurobiol. 2015;41:694-720.

25. Neumann JE, Dorostkar MM, Korshunov A, Mawrin C, Koch A, Giese A, Schüller U. Distinct Histomorphology in Molecular Subgroups of Glioblastomas in Young Patients. J Neuropathol Exp Neurol. 2016;75:408-14.

26. Hewer E, Prebil N, Berezowska S, Gutt-Will M, Schucht P, Dettmer MS, Vassella E. Diagnostic implications of TERT promoter mutation status in diffuse gliomas in a routine clinical setting. Virchows Arch. 2017;471:641-9.

27. Brat DJ, Aldape K, Colman H, Holland EC, Louis DN, Jenkins RB, Kleinschmidt-DeMasters BK, Perry A, Reifenberger G, Stupp R, von Deimling A, Weller M. cIMPACT-NOW update 3: Recommended diagnostic criteria for "Diffuse astrocytic glioma, IDH-wildtype, with molecular features of glioblastoma, WHO grade IV”. Acta Neuropathol. 2018;136:805-10.
28. Arita H, Yamasaki K, Matsushita Y, Nakamura T, Shimokawa A, Takami H, Tanaka S, Mukasa A, Shirahata M, Shimizu S, Suzuki K, Saito K, Kobayashi K, Higuchi F, Uzuka T, Otani R, Tamura K, Sumita K, Ohno M, Miyakita Y, Kagawa N, Hashimoto N, Hatae R, Yoshimoto K, Shinojima N, Nakamura H, Kanemura Y, Okita Y, Kinoshita M, Ishibashi K, Shofuda T, Kodama Y, Mori K, Tomogane Y, Fukai J, Fujita K, Terakawa Y, Tsuyuguchi N, Moriuchi S, Nonaka M, Suzuki H, Shibuya M, Maehara T, Saito N, Nagane M, Kawahara N, Ueki K, Yoshimine T, Miyaoka E, Nishikawa R, Komori T, Narita Y, Ichimura K. A combination of TERT promoter mutation and MGMT methylation status predicts clinically relevant subgroups of newly diagnosed glioblastomas. Acta Neuropathol Commun. 2016;4:79.

29. Heaphy CM, de Wilde RF, Jiao Y, Klein AP, Edil BH, Shi C, Bettegowda C, Rodriguez FJ, Eberhart CG, Hebbar S, Offerhaus GJ, McLendon R, Rasheed BA, He Y, Yan H, Bigner DD, ObaShinjo SM, Marie SK, Riggins GJ, Kinzler KW, Vogelstein B, Hruban RH, Maitra A, Papadopoulos N, Meeker AK. Altered telomeres in tumors with ATRX and DAXX mutations. Science. 2011;333:425.

30. Chan AK, Yao Y, Zhang Z, Chung NY, Liu JS, Li KK, Shi Z, Chan DT, Poon WS, Zhou L, Ng HK. TERT promoter mutations contribute to subset prognostication of lower-grade gliomas. Mod Pathol. 2015;28:177-86.

31. Labussière M, Di Stefano AL, Gleize V, Boisselier B, Giry M, Mangesius S, Bruno A, Paterra R, Marie Y, Rahimian A, Finocchiaro G, Houlston RS, Hoang-Xuan K, Idbaih A, Delattre JY, Mokhtari K, Sanson M. TERT promoter mutations in gliomas, genetic associations and clinico-pathological correlations. Br J Cancer. 2014; 111:2024-32.

32. Liu X, Wu G, Shan Y, Hartmann C, von Deimling A, Xing M. Highly prevalent TERT promoter mutations in bladder cancer and glioblastoma. Cell Cycle. 2013;12:1637-8.

33. Kaloshi G, Benouaich-Amiel A, Diakite F, Taillibert S, Lejeune J, Laigle-Donadey F, Renard MA, Iraqi W, Idbaih A, Paris S, Capelle L, Duffau H, Cornu P, Simon JM, Mokhtari K, Polivka M, Omuro A, Carpentier A, Sanson M, Delattre JY, Hoang-Xuan K. Temozolomide for low-grade gliomas: Predictive impact of $1 \mathrm{p} / 19 \mathrm{q}$ loss on response and outcome. Neurology. 2007;68:1831-6.

34. van den Bent MJ, Brandes AA, Taphoorn MJ, Kros JM, Kouwenhoven MC, Delattre JY, Bernsen HJ, Frenay M, Tijssen CC, Grisold W, Sipos L, Enting RH, French PJ, Dinjens WN, Vecht CJ, Allgeier A, Lacombe D, Gorlia T, Hoang-Xuan K. Adjuvant procarbazine, lomustine, and vincristine chemotherapy in newly diagnosed anaplastic oligodendroglioma: Long-term follow-up of EORTC brain tumor group study 26951. J Clin Oncol. 2013;31:344-50.

35. Aibaidula A, Chan AK, Shi Z, Li Y, Zhang R, Yang R, Li KK, Chung NY, Yao Y, Zhou L, Wu J, Chen H, Ng HK. Adult IDH wild-type lower-grade gliomas should be further stratified. Neuro Oncol. 2017;19:1327-37. 